
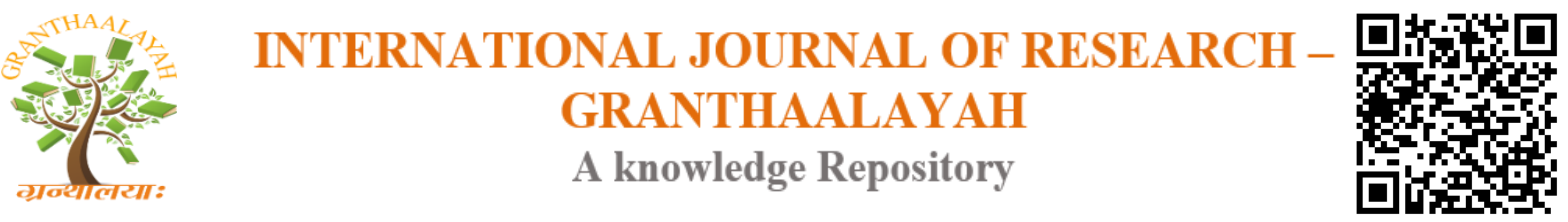

Social

\title{
DEVELOPMENT AND VALIDATION OF A TOOL ON COGNITIVE PERFORMANCE OF HIGH SCHOOL STUDENTS
}

\author{
T.Indumathi ${ }^{1}$, Dr. N. Ramakrishnan ${ }^{2}$ \\ ${ }^{1}$ Ph.D Scholar, Department of Educational Technology, Tamil Nadu Teachers Education \\ University, Karapakkam, Chennai - 600 097, India \\ ${ }^{2}$ Professor \& Head, Department of Educational Technology, Tamil Nadu Teachers Education \\ University, Karapakkam, Chennai - 600 097, India
}

\begin{abstract}
In the present study, Cognitive performance scale has been developed and validated of the High School Students. This scale consists of 58 statements. The simple random sample technique was used for this study. The sample consists of 50 High School Students are randomly selected from the Kancheepuram Districts. The ' $t$ ' value was used to standardize the tool and finally 37 statements were retained for the final study.
\end{abstract}

Keywords: Cognitive Performance; High School Students.

Cite This Article: T.Indumathi, and Dr. N. Ramakrishnan. (2017). "DEVELOPMENT AND VALIDATION OF A TOOL ON COGNITIVE PERFORMANCE OF HIGH SCHOOL STUDENTS." International Journal of Research - Granthaalayah, 5(8:SE), 100-105. https://doi.org/10.29121/granthaalayah.v5.i8(SE).2017.2284.

\section{Introduction}

The cognitive performance refers to a set of psychological processes associated with so called higher cognitive or thought processes which corresponds with adaptive and future oriented behavior unique to humans.

\section{Definition of Cognitive performance}

In cognitive psychology, the term 'performance' refers to the measurement of several processes that can be represented both in cognitive and somatic functions of the brain. "The term performance denotes abilities and skills from the psychological functional ranges of perception, attention (concentration), learning and retention, thinking and intelligence, and psychomotor activity, all of which can be assessed by test".

So, cognitive performance is not defined by a single value like the intelligence quotient but rather as a combination of performance of several cognitive functions and processes (Budde and Barkowsky, 2008). 


\section{Objectives of the Study}

The objective of the present investigation is to develop a tool to measure the cognitive performance of high school students. As there is no suitable tool available for the purpose the investigator has constructed and validated one in order to realize her objectives. The Cognitive Performance Inventory (CPI) is a five point scale. i.e. "Likert-type scale".

\section{Pilot Study}

This inventory of 58 statements intended for pilot study was administrated to the sample, 50 high school students studying in the Kancheepuram district. Then their responses have been scored carefully and the marks secured by all the students have been arranged in the descending order from the highest score to lowest score. Then, they were subjected to item analysis.

\section{Item Analysis}

The next step in the standardization of cognitive performance inventory after pilot study is to find out the ' $t$ ' value of each statement which forms the basis for item selection in order to build up the final inventory.

The Likert-type scale calls for a graded response to each statement on a five-point scale ranging from "Strongly Agree (SA)", "Agree (A)", Uncertain (UC)", Disagree (DA)" and "Strongly Disagree (SDA)". The different points on the scale are assigned arbitrary weights, for example 5, 4, 3, 2 and 1 in the order of response for the positive statements (43 items). The scoring scheme is reversed for the negative statements (15 items). The scoring key given in below Table -1 .

Table 1: Scoring key of the inventory according to the nature of items

\begin{tabular}{|l|l|l|l|l|l|}
\hline Nature of the Items & Strongly Agree & Agree & Uncertain & Disagree & $\begin{array}{l}\text { Strongly } \\
\text { Disagree }\end{array}$ \\
\hline $\begin{array}{l}\text { Positive: } 1,2,4,5,6,7,9,11, \\
12,13,15,17,18,19,20,22,27,\end{array}$ & $\mathbf{5}$ & $\mathbf{4}$ & $\mathbf{3}$ & $\mathbf{2}$ & $\mathbf{1}$ \\
$\begin{array}{l}28,30,31,32,34,35,36,37,38, \\
40,41,43,44,45,46,47,48,49, \\
50,51,52,54,55,56,57,58 .\end{array}$ & & & & & \\
\hline $\begin{array}{l}\text { Negative: } 3,8,10,14,16,21, \\
23,24,25,26,29,33,39,42,53 .\end{array}$ & $\mathbf{1}$ & $\mathbf{2}$ & $\mathbf{3}$ & $\mathbf{4}$ & $\mathbf{5}$ \\
\hline
\end{tabular}

Table 2: Cognitive performance Inventory Dimension wise according to the nature of items

\begin{tabular}{|c|c|c|c|}
\hline \multirow{3}{*}{$\begin{array}{l}\text { Dimension } \\
\text { Memory }\end{array}$} & \multicolumn{2}{|c|}{ Nature of the Items } & \multirow{3}{*}{$\begin{array}{l}\text { Total } \\
16\end{array}$} \\
\hline & Positive & $1,2,4,5,6,7,9,11,12,13,15$ & \\
\hline & Negative & $3,8,10,14,16$ & \\
\hline \multirow[t]{2}{*}{ Attention } & Positive & $17,18,19,20,22,27$ & \multirow[b]{2}{*}{11} \\
\hline & Negative & $21,23,24,25,26$ & \\
\hline \multirow[t]{2}{*}{ Flexibility } & Positive & $28,30,31,32,34,35,36,37,38$ & \multirow[b]{2}{*}{12} \\
\hline & Negative & $29,33,39$ & \\
\hline \multirow[t]{2}{*}{ Self-Perception } & Positive & $40,41,43,44,45,46,47$ & \multirow[b]{2}{*}{8} \\
\hline & Negative & 42 & \\
\hline \multirow[t]{2}{*}{ Thinking } & Positive & $48,49,50,51,52,54,55,56,57,58$ & \multirow[b]{2}{*}{11} \\
\hline & Negative & 53 & \\
\hline & & Total & 58 \\
\hline
\end{tabular}


Table 3: Cognitive performance Inventory dimension wise according to the selected items

\begin{tabular}{|c|c|c|c|}
\hline \multirow{3}{*}{$\begin{array}{l}\text { Dimension } \\
\text { Memory }\end{array}$} & \multicolumn{2}{|c|}{ Nature of the Items } & \multirow{3}{*}{$\begin{array}{l}\text { Total } \\
11\end{array}$} \\
\hline & Positive & $1,2,4,6,7,11,12,13,15$ & \\
\hline & Negative & 10,16 & \\
\hline \multirow[t]{2}{*}{ Attention } & Positive & $17,18,19,20$ & \multirow[b]{2}{*}{7} \\
\hline & Negative & $23,25,26$ & \\
\hline \multirow[t]{2}{*}{ Flexibility } & Positive & $30,34,35,37$ & \multirow[b]{2}{*}{6} \\
\hline & Negative & 33,39 & \\
\hline \multirow[t]{2}{*}{ Self-Perception } & Positive & $40,44,45,46,47$ & \multirow[b]{2}{*}{5} \\
\hline & Negative & - & \\
\hline \multirow[t]{2}{*}{ Thinking } & Positive & $50,52,54,55,56,57,58$ & \multirow[b]{2}{*}{8} \\
\hline & Negative & 53 & \\
\hline & & Total & 37 \\
\hline
\end{tabular}

\section{Items Selection}

To select the items to from the final draft of the Cognitive Performance Inventory, the difficulty index of the each item was analyzed. According to Edwards (1957), "the value of ' $t$ ' is a measure of the extent to which a given item differentiates between the high and low groups. If the ' $t$ ' value is equal to or greater than 1.96, it indicates that the average response of the high and low groups to a statement differs significantly, provided here are 14 or more subjects in the high group and also in the low group".

The ' $t$ ' value for all the 58 items of the CPI were obtained to select the items for the final draft. Out of 58 items, 37 items were found to be selected as having ' $t$ ' value more than 1.96. They are given in table -4 .

Table 4: Items selected for the draft of the CPI based on their ' $t$ ' value between upper and lower

\begin{tabular}{|l|l|l|l|}
\hline Item No. & 't' Value & Remarks & $\begin{array}{l}\text { Item No. in the final draft of } \\
\text { Cognitive performance }\end{array}$ \\
\hline 1 & $\mathbf{2 . 5 0 0}$ & Selected & $\mathbf{1}$ \\
\hline 2 & $\mathbf{2 . 3 8 6}$ & Selected & $\mathbf{2}$ \\
\hline 3 & 0.126 & Not Selected & - \\
\hline 4 & $\mathbf{3 . 4 8 4}$ & Selected & $\mathbf{3}$ \\
\hline 5 & 1.161 & Not Selected & - \\
\hline 6 & $\mathbf{4 . 2 0 4}$ & Selected & $\mathbf{4}$ \\
\hline 7 & $\mathbf{2 . 6 2 1}$ & Selected & $\mathbf{5}$ \\
\hline 8 & 0.611 & Not Selected & - \\
\hline 9 & 0.380 & Not Selected & - \\
\hline 10 & $\mathbf{2 . 3 5 6}$ & Selected & $\mathbf{6}$ \\
\hline 11 & $\mathbf{4 . 1 6 3}$ & Selected & $\mathbf{7}$ \\
\hline 12 & $\mathbf{2 . 0 5 3}$ & Selected & $\mathbf{8}$ \\
\hline 13 & $\mathbf{2 . 8 7 9}$ & Selected & $\mathbf{9}$ \\
\hline 14 & 1.000 & Not Selected & - \\
\hline 15 & $\mathbf{2 . 1 1 0}$ & Selected & $\mathbf{1 0}$ \\
\hline 16 & $\mathbf{2 . 3 4 0}$ & Selected & $\mathbf{1 1}$ \\
\hline 17 & $\mathbf{2 . 2 2 3}$ & Selected & $\mathbf{1 2}$ \\
\hline 18 & $\mathbf{3 . 3 4 7}$ & Selected & $\mathbf{1 3}$ \\
\hline
\end{tabular}




\begin{tabular}{|c|c|c|c|}
\hline 19 & 3.631 & Selected & 14 \\
\hline 20 & 2.623 & Selected & 15 \\
\hline 21 & 1.636 & Not Selected & - \\
\hline 22 & 0.366 & Not Selected & - \\
\hline 23 & 3.000 & Selected & 16 \\
\hline 24 & 0.400 & Not Selected & - \\
\hline 25 & 7.948 & Selected & 17 \\
\hline 26 & 2.261 & Selected & 18 \\
\hline 27 & 0.465 & Not Selected & - \\
\hline 28 & 1.908 & Not Selected & - \\
\hline 29 & 0.434 & Not Selected & - \\
\hline 30 & 2.876 & Selected & 19 \\
\hline 31 & 0.979 & Not Selected & - \\
\hline 32 & 0.586 & Not Selected & - \\
\hline 33 & 2.066 & Selected & 20 \\
\hline 34 & 3.553 & Selected & 21 \\
\hline 35 & 2.590 & Selected & 22 \\
\hline 36 & 0.945 & Not Selected & - \\
\hline 37 & 3.319 & Selected & 23 \\
\hline 38 & 1.145 & Not Selected & - \\
\hline 39 & 2.154 & Selected & 24 \\
\hline 40 & 3.347 & Selected & 25 \\
\hline 41 & 1.336 & Not Selected & - \\
\hline 42 & 0.747 & Not Selected & - \\
\hline 43 & 0.231 & Not Selected & - \\
\hline 44 & 3.465 & Selected & 26 \\
\hline 45 & 4.413 & Selected & 27 \\
\hline 46 & 4.048 & Selected & 28 \\
\hline 47 & 3.800 & Selected & 29 \\
\hline 48 & 1.847 & Not Selected & - \\
\hline 49 & 0.000 & Not Selected & - \\
\hline 50 & 3.889 & Selected & 30 \\
\hline 51 & 0.576 & Not Selected & - \\
\hline 52 & 4.020 & Selected & 31 \\
\hline 53 & 4.702 & Selected & 32 \\
\hline 54 & 2.621 & Selected & 33 \\
\hline 55 & 3.242 & Selected & 34 \\
\hline 56 & 2.347 & Selected & 35 \\
\hline 57 & 1.961 & Selected & 36 \\
\hline 58 & 3.823 & Selected & 37 \\
\hline
\end{tabular}

Here, the investigator has mentioned 37 selected statements in below Table - 5

Table 5:

\begin{tabular}{|c|c|c|c|c|c|c|}
\hline S. No. & Statements; & 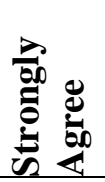 & 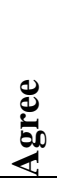 & 莞 & 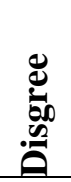 & 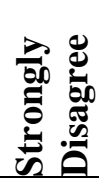 \\
\hline & MEMORY & & & & & \\
\hline 1. & I remember concepts through written practice. & & & & & \\
\hline
\end{tabular}




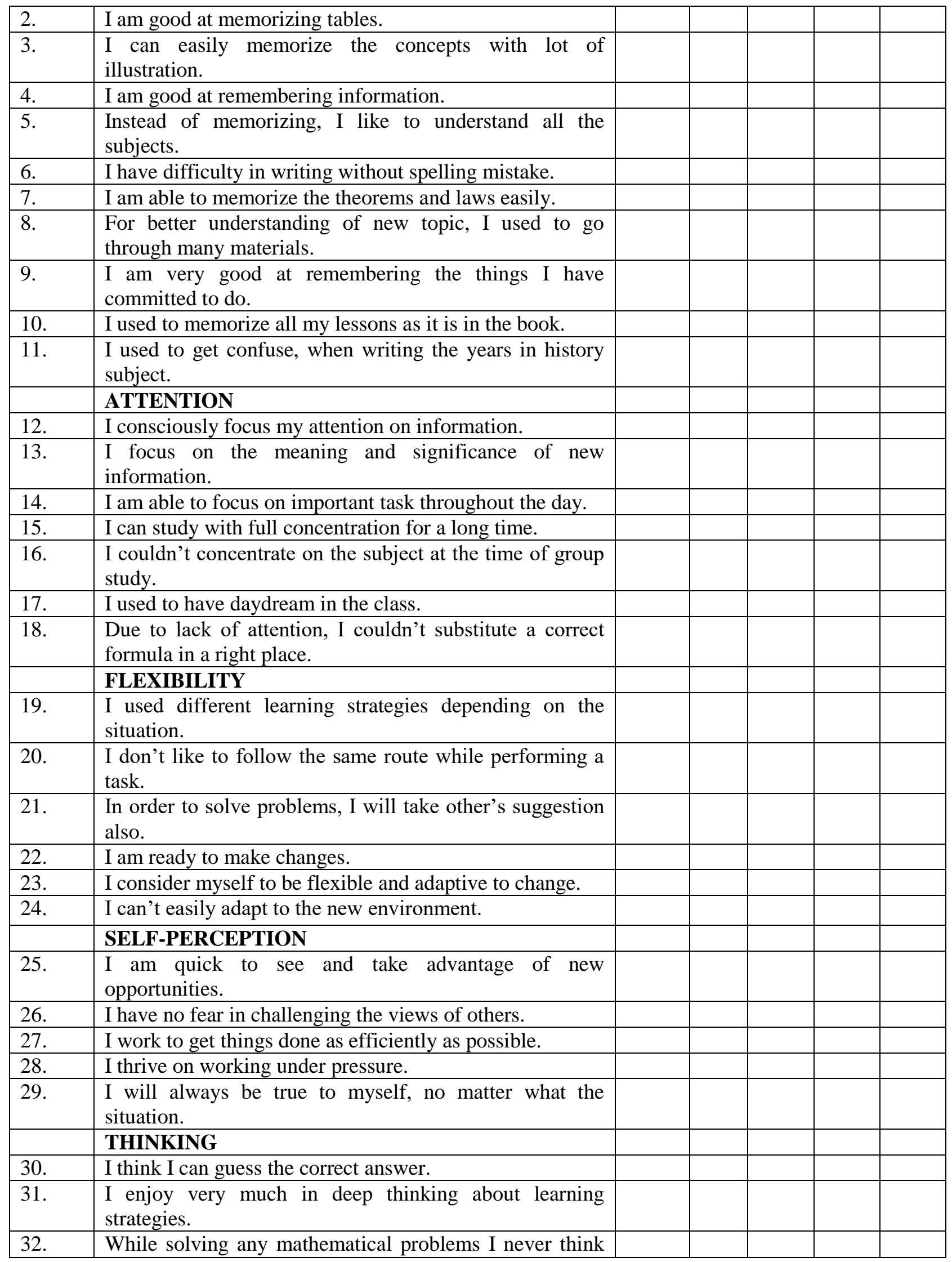




\begin{tabular}{|l|l|l|l|l|l|l|}
\hline & about the step to follow. & & & & & \\
\hline 33. & $\begin{array}{l}\text { I think of several ways to solve a problem and choose the } \\
\text { best one. }\end{array}$ & & & & & \\
\hline 34. & I am proud that I can think correct answer. & & & & & \\
\hline 35. & I usually think of different ways to answer a question. & & & & & \\
\hline 36. & $\begin{array}{l}\text { I used to memorize my science lessons as it is, without } \\
\text { thinking and analyzing about the scientific facts. }\end{array}$ & & & & & \\
\hline 37. & $\begin{array}{l}\text { I used to think about the easy method to solve any } \\
\text { calculations. }\end{array}$ & & & & \\
\hline
\end{tabular}

\section{Reliability}

In order to establish the reliability of Cognitive Performance inventory, the spilt-Half method was used. The reliability of Cognitive Performance inventory was found to be 0.95 . Hence, Cognitive Performance inventory was considered as reliable.

\section{Validity}

The index of validity which is the square root of the reliability was found to be 0.97 . Hence, Cognitive Performance inventory selected for the study was considered to be highly valid.

\section{Conclusion}

The investigator is hopeful that this inventory would be helpful to measure the level of Cognitive Performance in the high school students. Hence, this tool will be very useful for the investigator to measure to what extent the level of Cognitive Performance is in the High School Students and it may be utilized and extended in the same for the future researchers.

\section{References}

[1] Dr. Neha Mishra. (2016). "Effect of breakfast on cognitive performance of Indian school student". International Journal of Home Science 2016; 2(1): 181-185.

[2] Golden, S. A. R. (2011). Problems and Prospectus of Distance Education. Quality Enhancement In Distance Education For Life Long Learning, 1(1), 343-344.

[3] Golden, S. A. R. (2016). Rural Students'attitude Towards English As Medium Of Instruction In Higher Education-An Analysis. International Journal of Research, 3, 1-10.

[4] Golden, S. A. R. (2017). Attitude of Students and Teachers towards E-Learning-An Analysis. Recent Research in Social Science \& Humanities, 1, 5-10.

[5] Golden, S. A. R. (2017). Recent Research in Social Sciences \& Humanities. EduPedia Publications (P) Ltd.

[6] John. W. best, "Research in Education", 4th Edition, Prentice Hall of India (P) Ltd., New Delhi,

[7] Kothari, C. R. (2000). "Research Methodology"; Methods and Practice Techniques, Wishwa Publication, New Delhi.

[8] Nisha khan \& Dr. Sunita Gupta. (2012). "Effects of Temperamental Dimensions, Food Intake And Gender On Cognitive Performance". Guru Nanak Dev University, Amritsar-143005, India.

[9] Rahul. A. G \& Dr. Joseph. M.I. (2009). "Effect of Meditation On Anxiety And Concomitant Cognitive Performance”. Sree Sankaracharya University of Sanskrit, Kalady, Kerala, India. 